\title{
Recognition of the 24-hour Noise Exposure of a Human
}

\author{
Tomasz KORBIEL, Bartłomiej STĘIEŃ, Wojciech BATKO, Robert BARAŃSKI \\ Dominik MLECZKO, Paweł PAWLIK, Jędrzej BLAUT \\ AGH University of Science and Technology \\ Department of Mechanics and Vibroacoustics \\ al. A. Mickiewicza 30, 30-059 Kraków, Poland; e-mail: tkorbiel@agh.edu.pl
}

(received March 8, 2017; accepted May 25, 2017)

\begin{abstract}
The civilisation progress has caused noise to become one of essential pathogenic and life comfort decreasing factors. There are several legal regulations aimed at controlling the noise influence on humans. Assessment of the twenty-four-hour influence of noises in various environments constitutes an essential problem. The answer can be supplied by 24 -hour monitoring of the sound pressure. This paper is an attempt to learn the real loading of humans by noises. A personal noise indicator was used in measurements. The human 24-hour activity was divided into cycles allowing to model noise hazards. The collected data, even though they did not signal exceeding of individual standards, in the 24-hour period indicated the essential noise influence. These results indicate the need of investigations to recognise the 24-hour noise load of a human, with taking into account various forms of their activity and the need of rest.
\end{abstract}

Keywords: noise hazard; 24-hour noise exposure; Personal Indicator of Noise Hazard; acoustic monitoring.

\section{Introduction}

In the contemporary industrial environment humans are subjected to several pathogenic and decreasing life comfort factors. One of such highly important factors is noise. It is understood as straining the human organism with undesired or harmful sounds when a person spends time in various places within their life activity. Various criteria of noise hazards assessments are binding for dependence on the noise influence place on the human organism. There are also various requirements concerning investigations. Investigating procedures of controlling and assessing noise hazards in work places are related to the binding Regulation of the Minister of Labour and Social Policy (Regulation of he Minister of Labour and Social Policy, 2014). In assessing the environment noises the Regulation of the Minister of Environment (Announcement of the Minister of Environment, 2013), is valid, while in assessing noises to which a person is exposed in buildings, the Polish Standard PN-87/B-02151/02 (1987) is binding. Notwithstanding the fact that a person is the subject of these regulations, they are treated differently in each of them and their exposure to noise hazards is quantified differently.
Thus, a natural question of a real 24-hour noise exposure of a human organism arises. Effects of mutual connections of noise exposures in various places and times should be taken into consideration. They should allow to reveal and properly quantify factors of an essential influence on inconveniences of noise processes in the human life.

Realisation of such investigations required development of the measuring tools adjusted for the research task, especially their miniaturisation creating conditions for a convenient 24-hour monitoring of noise exposure of the human organism.

Harmful noise influence depends on the length of time, sound pressure level, frequency spectrum, and time character. Individual sensitivity to noise influences is also very important. Harmful noise influences are related both to acoustic and not acoustic effects. The most fragment case is increasing the auditory threshold, called the loss of hearing. Mainly, the first symptoms are problems with hearing certain (usually higher) frequencies. The basic assessment of the noise influence on hearing organs is performed by the tonal audiometry (Announcement of the Minister of Health, 2016). Measurements of otoacoustic emission can constitute an alternative for the tonal audiome- 
try (Report of an International Expert Symposium, 2011). Examinations of hearing organs' defects under the sound wave influence performed by means of otoacoustic emission methods allowed to develop noise influence indicators. Hoтz et al. (1993) estimated the hearing state by means of the tonal audiometry and Transient Evoked Otoacoustic Emissions (TEOAE). Numerous examinations, among young persons and children, started in 1990's. The obtained results indicated hearing losses exceeding $20 \mathrm{~dB}$ HL in more than $30 \%$ of examined people (JAROsZEwski, 2000). At the beginning of this century the tests were confirmed and indicated growing tendencies. Noises as harmful elements became one of the most serious threats of the contemporary society (KORADECKA, 2010). Noise influence on the human vascular system operation was measured on the sample of 513 people (DzhAmbov, Dimitrova, 2016). It was found that noise above $65 \mathrm{~dB}$ increases the risk of the heart ischaemia occurrence. Also, the research proves association between ischemic heart disease and noise pollution (SWINBURN et al., 2015). Moreover, this work contains discussion of economic aspects associated with this problem. Investigations concerning exposure to noises generated by wind turbines (HAFKE-Dys et al., 2016; WSZOEEK et al., 2014), or aircraft (MAKAREwICZ et al., 2014) can be found in literature.

Another very serious problem is the noise influence without acoustic effects. In such cases the problem is not in the acoustic signal level but in its inconvenience for an individual. This is a phenomenon difficult for describing in any standard way, since it strongly depends on individual predispositions of a person exposed to noises.

This study undertakes the problem of assessing the 24-hour noise exposure of a person as well as analyses of presently applied parameters. In the majority of parameters determining noise exposures the equivalent sound pressure level is applied. There are experimental proofs, that longer exposures are more harmful for hearing than shorter ones, and that interrupted noises cause smaller damages than continuous ones. However, applying this rule in relation to impulse noises is controversial. This type of noise is especially harmful, since it is characterised by such a fast increase of the sound pressure that protection mechanisms of hearing organs (stirrup reaction) being of a certain inertia are not efficient (PAWLACZYK-ŁUSZCZYŃSKA et al., 2010).

For these reasons the main objective of Kosała's research was development of an innovative method to assess the noise hazard in the working environment in quarries. The method was based on the single number global index, which is an approximate general measure and the function of four partial indices: the noise hazard index at the workstation, sound power of the machines index, continuous noise index, and impulse noise index (KosatA, StęPIEŃ, 2016).

\section{Methodology of measurements}

European (European Parliament, 2002) and domestic (Announcement of the Marshal of the Polish Sejm, 2016) regulations oblige to perform complex assessments of the environment acoustic state and to undertake proper operations to reduce the excessive acoustic influences on the environment. To achieve this purpose it is necessary to develop - common for all European Union member countries - methods and noise assessment indicators, strategic acoustic maps, as well as environment protection programs. Detailed requirements concerning environment protection programs against noises are in the Regulation of the Minister of Environment (2002).

In 2005, based on the Environment Protection Act (Amendment to the Act - Environment Protection Law, 2005), the legislator introduced a new institution of the so-called noise indicators. Presently, they constitute the basis for the long-term policy in the environment protection against noises as well as for the determination and control of noise emission conditions.

The first indicator, used for performing the longterm policy in the environment protection against noises, is the long-term average sound level $L_{\mathrm{DEN}}$ and long-term night sound level $L_{\mathrm{N}}$. The A-weighted equivalent sound pressure level for the day time $L_{\text {Aeq, D }}$ and the A-weighted equivalent sound pressure level for the night time $L_{\text {Aeq, N }}$ are indicators applied for determining and controlling conditions of using the environment.

The presented above noise indicators (long-term and related to 24-hour only) were utilised for setting up the environment acoustic climate standards, which is the subject of the Announcement of the Minister of Environment (2013), concerning the uniform text of the Regulation of the Minister of Environment on allowable noise levels in the environment (Journal of Laws 2014, item 112, Announcement of the Minister of Environment, 2013). The above regulations to a large measure protect the environment against noises emitted by humans, while only indirectly protect humans being in this environment.

Allowable noise levels in accommodations destined for people are determined by standard PN-87/B$02151 / 02$ (1987). The assessment is done only on the basis of the A-weighted equivalent sound pressure level. The measuring method is also doubtful, since it is required that windows and doors of accommodation be closed and that only two people can be present inside the tested place during measuring. Such conditions do not allow a real assessment of noise influence on users. This standard does not take into account tonal noise components and level diversities, which can cause subjective impressions of higher inconvenience than it would result from the measured A-weighted sound pressure level. 
The noise assessment in the work place is carried out on the basis of the Maximum Permissible Intensity (MPI) values, which are determined in the Regulations of the Minister of Labour and Social Policy (2014). According to these Regulations a noise in the work environment is characterised by:

- noise exposure level related to 8-hour period of the 24-hour work time or the noise exposure level related to the working week,

- daily noise exposure related to 8-hour period of the 24-hour work time or the noise exposure related to the working week,

- A-weighted maximum sound pressure level,

- C-weighted sound peak pressure level.

A person being a worker, environment participant, and inhabitant, is exposed to noises which are assessed by means of separate directives and regulations. In addition, these directives are not additive. This means that a complex assessment of noise influence is impossible. In regulations related to work places the exposition to noise and the exposition noise level are essential factors, while the need of resting is taken into account to a very small degree only. In assessments of environmental noises the short-term and long-term indicators, which are taking into account a time of the day, i.e. day, evening, and night, are used. In accommodations destined for people the noise assessment is done by means of the A-weighted equivalent sound pressure level divided into day and night times.

The aim of the carried out studies is the determination of the human 24-hour noise exposure. The preliminary determination of this noise exposure requires certain assumptions characterising the 24-hour activity of a human. The authors divided this activity cycle into three main periods:

1) work period of 8 hours, from 08:00 to 16:00;

2) not professional activity period of 10 hours, from 06:00 to 08:00 and from 16:00 to 24:00;

3 ) rest period of 6 hours, from 00:00 to 06:00.

The presented above division of the 24-hour period of the human activity is a general one. Boundaries of these periods and their length can differ for each tested person. It depends on the professional work kind, family situation, and individual properties.

For the needs of the hereby studies the 24-hour period was divided into five periods related to the human activity:

1) sleep time of 6 hours, from 00:00 to 06:00;

2) time of morning preparations of 1.5 hours, from 06:00 to $07: 30$;

3) time of travelling to and from work of 1 hour duration, from 07:30 to 08:00 and from 16:00 to 16:30;

4) work time of 8 hours, from 08:00 to 16:00;

5) private time of 7.5 hours, from 16:30 to 24:00.

\section{Results of acoustic measurements}

Measurements of the A-weighted sound pressure level were performed using the Personal Indicator of Noise Hazard (PINH) developed within the 3rd stage of multiyear program: "Improvement of safety and work conditions", financed in 2014-2016 within the scope of research and development works by the Ministry of Science and Higher Education/National Centre of Research and Development. The Central Institute for Labour Protection - National Research Institute (CIOP-PIB) was the Program Coordinator. Device $\mathrm{PINH}$ is equipped with a sensory system consisting of a microphone and a vibration sensor. PINH performs a full range of measurements corresponding to the functionality of the acoustic dosimeter. The device is additionally equipped with an innovative system of mechanical interactions reduction, because accidental or deliberate impacts on the microphone cause significant measurement errors. Using the PINH instead of standard dosimeters allowed a 24 hour long monitoring of noise exposure without a direct involvement of qualified personnel. This also allowed the elimination of accidental or deliberate mechanical effects on the measuring system (BATKO et al., 2016).

This 24-hour noise exposure was monitored for the coal yard employee, whose duties are trading, loading and transportation of coal. The PINH recorded the A-weighted sound pressure level during 24 hours in all places where the tested person was present. The time plot of the recorded quantity is presented in Fig. 1 as a grey line.

The places in which the person was present can be divided into three groups: home and work environments and the public transport.

The person in the home environment performs functions related to three kinds of activities, i.e., sleep time, morning preparations, and private time. Measurements in the home environment were done during typical activities such as: sleep, morning and evening preparations, preparations of meals, watching television, using computer, and talking with household members.

Noise exposures in the work environment was monitored during typical tasks of the work time. The tested employee's duties were coal loading, transportation of products to clients, and servicing the technological line of coal breaking up. For travelling to and from work place this employee was using the municipal transport system.

Measurements were carried out on the basis of 24hour recording of the A-weighted sound pressure level. This is one of the measurement strategies described in the PN-EN ISO 9612:2011 (2011).

This measurement strategy is based on the signal recording for 24-hour activity period of a human in every place where the person was present during each ac- 


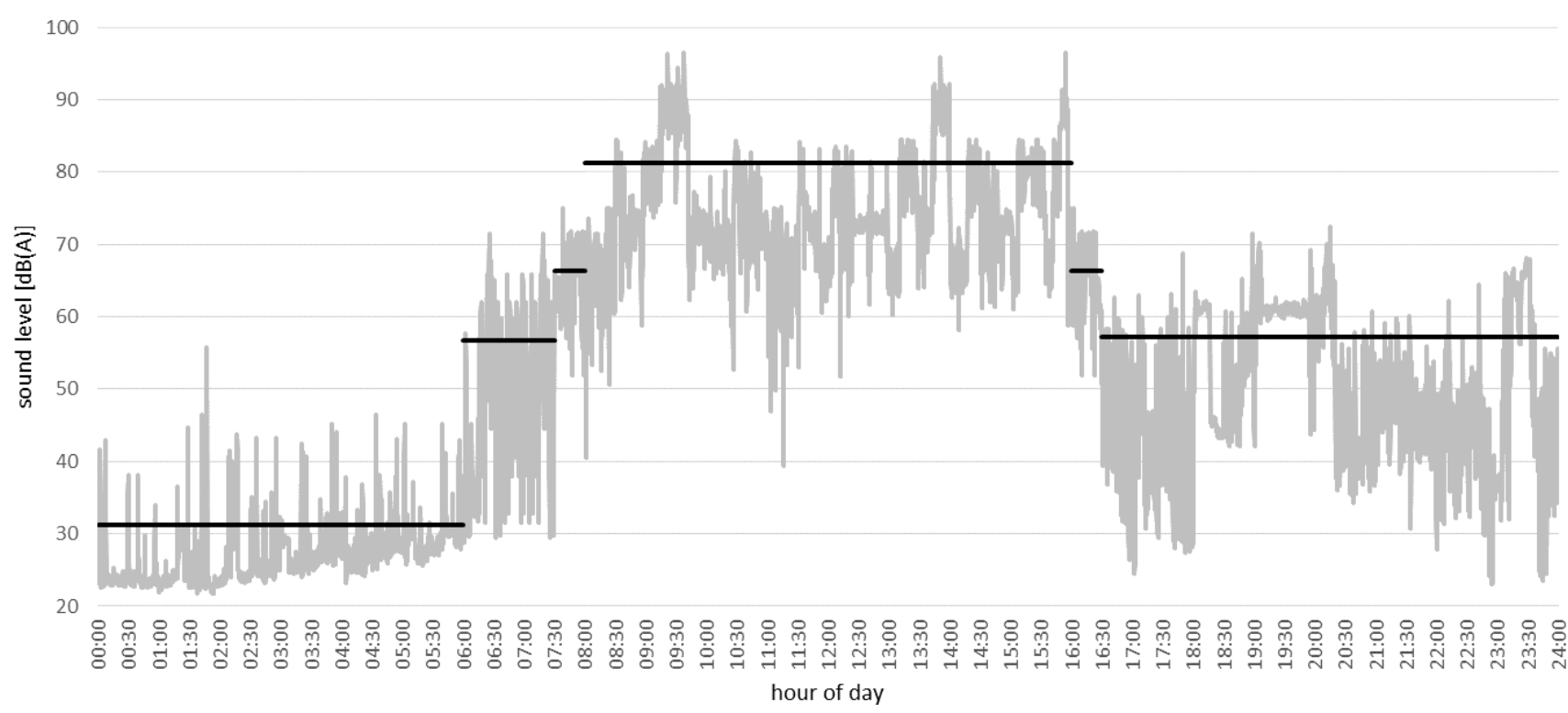

Fig. 1. Variability of the A-weighted sound pressure level in the 24-hour period (grey line). The black solid line shows the A-weighted equivalent sound pressure level for each human activity period presented in Table 1.

Table 1. A-weighted equivalent sound pressure level during 24 hours of the human activity. The activities performed during each period are listed in the last column.

\begin{tabular}{|c|c|c|}
\hline Activity period & $\begin{array}{c}\text { A-weighted equivalent } \\
\text { sound pressure level }[\mathrm{dB}]\end{array}$ & Activities \\
\hline Sleep time & 31.3 & sleep \\
\hline Time of morning preparation & 56.8 & morning toilet, breakfast preparation \\
\hline Time of travelling to and from work & 66.4 & travelling by municipal transport \\
\hline Work time & 81.2 & activities related to professional work \\
\hline Private time & 57.2 & $\begin{array}{c}\text { house cleaning, using computer, } \\
\text { watching television, evening toilet, } \\
\text { talking with household members }\end{array}$ \\
\hline
\end{tabular}

tivity (mentioned in Table 1). The measuring time, in depending on the activity, in a determined place took from several dozen minutes (e.g., municipal transport, cleaning) to a couple of hours (sleep, work period, multimedia activity, shopping, visits in public places). In each case the microphone was attached near the ear. That allows to gain the most accurate reproduction of conditions under which the sound perception occurs. The sound pressure level measurement was carried out with using A-weighting curve, which was the cause of the fact that the subjective sound reception by a human could differ from the measurement results.

For each activity period presented in Table 1 the A-weighted equivalent sound pressure level $\left(L_{\text {Aeq }}\right)$ was determined. Its pathway is presented in a schematic way in Fig. 1. This way of presentation of $L_{\text {Aeq }}$ shows clearly how noise exposure values change in different periods. On the basis of that, it is easy to see that the lowest levels refers to the sleep time, while the highest levels refer to the work time. In the presented case the results show an important impact of noise during travelling time in assessment of noise exposure. On the other hand, the value of the A-weighted equivalent sound pressure level during the private time has insignificant effect on values of calculated noise indicators. This is because the $L_{\text {Aeq }}$ level registered during the private time is $20 \mathrm{~dB}$ lower than during the work time.

On the basis of the performed measurements and the information of noise exposure times the following indicators were determined:

- $L_{\text {Aeq }(24 \mathrm{~h})}-\mathrm{A}$-weighted equivalent sound pressure level for 24-hour period [dB],

- $L_{\mathrm{D}(6-22)}$ - A-weighted equivalent sound pressure level during the day time from 6:00 to 22:00 [dB],

- $L_{\mathrm{N}(22-6)}-\mathrm{A}$-weighted equivalent sound pressure level during the night time from 22:00 to 6:00 [dB],

- $L_{\text {Aeq, D }}$ - A-weighted equivalent sound pressure level during the day time in 8 most disadvantageous hours occurring one after another $[\mathrm{dB}]$, 
- $L_{\text {Aeq, N }}-$ A-weighted equivalent sound pressure level during the night time in one most disadvantageous hour $[\mathrm{dB}]$,

- $L_{\mathrm{DEN}(24 \mathrm{~h})}$ - long-term average sound level, for 24hour period $[\mathrm{dB}]$,

- $E_{24 \mathrm{~h}}$ - total sound exposure, for 24-hour period $\left[\mathrm{Pa}^{2} \cdot \mathrm{s}\right]$,

- $E_{8 \mathrm{~h}(24 \mathrm{~h})}$ - total sound exposure, for 24-hour period, referred to 8-hour work time $\left[\mathrm{Pa}^{2} \cdot \mathrm{s}\right]$,

- $E_{8 \mathrm{~h}(6-18)}$ - total sound exposure, for 12 hours from 6:00 to 18:00, referred to 8-hour work time $\left[\mathrm{Pa}^{2} \cdot \mathrm{s}\right]$,

- $E_{8 \mathrm{~h}(18-6)}$ - total sound exposure for 12 hours from 18:00 to 6:00, referred to 8-hour work time $\left[\mathrm{Pa}^{2} \cdot \mathrm{s}\right]$,

- $E_{8 \mathrm{~h}(6-22)}$ - total sound exposure in a day time, from 6:00 to 22:00, referred to 8-hour work time $\left[\mathrm{Pa}^{2} \cdot \mathrm{s}\right]$,

- $E_{8 \mathrm{~h}(22-6)}$ - total sound exposure in a night time, from 22:00 to 6:00, referred to 8-hour work time $\left[\mathrm{Pa}^{2} \cdot \mathrm{s}\right]$,
- $L_{\mathrm{EX}(24 \mathrm{~h})}$ - noise exposure level for 24-hour period $[\mathrm{dB}]$,

- $L_{\mathrm{EX}, 8 \mathrm{~h}(24 \mathrm{~h})}$ - noise exposure level for 24-hour period, referred to 8-hour work time [dB],

- $L_{\mathrm{EX}, 8 \mathrm{~h}(6-18)}$ - noise exposure level for 12 hours, from 6:00 to 18:00, referred to 8-hour work time $[\mathrm{dB}]$,

- $L_{\mathrm{EX}, 8 \mathrm{~h}(18-6)}$ - noise exposure level for 12 hours, from 18:00 to 6:00, referred to 8-hour work time $[\mathrm{dB}]$,

- $L_{\mathrm{EX}, 8 \mathrm{~h}(6-22)}$ - noise exposure level in a day time, from 6:00 to 22:00, referred to 8-hour work time $[\mathrm{dB}]$,

- $L_{\mathrm{EX}}, 8 \mathrm{~h}(22-6)-$ noise exposure level in a night time, from 22:00 to 6:00, referred to 8-hour work time $[\mathrm{dB}]$.

The listed above noise indicators describe noise hazards for humans in various places of their presence whose values are presented in Table 2 .

Table 2. Values of the determined noise indicators.

\begin{tabular}{|c|c|c|}
\hline Noise indicator & Value & Allowable value \\
\hline$L_{\text {Aeq }(24 \mathrm{~h})}[\mathrm{dB}]$ & 76.5 & no data \\
\hline$L_{\mathrm{D}(6-22)}[\mathrm{dB}]$ & 79.5 & $50-68^{*}$ \\
\hline$L_{\mathrm{N}(22-6)}[\mathrm{dB}]$ & 51.2 & $45-60^{*}$ \\
\hline$L_{\text {Aeq,D }}[\mathrm{dB}]$ & 81.2 & $45-55^{*}, 30-45^{* *}$ \\
\hline$L_{\mathrm{Aeq}, \mathrm{N}}[\mathrm{dB}]$ & 57.2 & $40-45^{*}, 30-40^{* *}$ \\
\hline$L_{\mathrm{DEN}(24 \mathrm{~h})}[\mathrm{dB}]$ & 76.5 & $45-70^{*}$ \\
\hline$E_{24 \mathrm{~h}}\left[\mathrm{~Pa}^{2} \cdot \mathrm{s}\right]$ & 1531.6 & no data \\
\hline$E_{8 \mathrm{~h}(24 \mathrm{~h})}\left[\mathrm{Pa}^{2} \cdot \mathrm{s}\right]$ & 1531.6 & $3640^{* * *}$ \\
\hline$E_{8 \mathrm{~h}(6-18)}\left[\mathrm{Pa}^{2} \cdot \mathrm{s}\right]$ & 1527.1 & $3640^{* * *}$ \\
\hline$E_{8 \mathrm{~h}(18-6)}\left[\mathrm{Pa}^{2} \cdot \mathrm{s}\right]$ & 4.5 & $3640^{* * *}$ \\
\hline$E_{8 \mathrm{~h}(6-22)}\left[\mathrm{Pa}^{2} \cdot \mathrm{s}\right]$ & 1530.1 & $3640^{* * *}$ \\
\hline$E_{8 \mathrm{~h}(22-6)}\left[\mathrm{Pa}{ }^{2} \cdot \mathrm{s}\right]$ & 1.5 & $3640^{* * *}$ \\
\hline$L_{\mathrm{EX}(24 \mathrm{~h})}[\mathrm{dB}]$ & 76.5 & no data \\
\hline$L_{\mathrm{EX}, 8 \mathrm{~h}(24 \mathrm{~h})}[\mathrm{dB}]$ & 81.2 & $85^{* * *}$ \\
\hline$L_{\mathrm{EX}, 8 \mathrm{~h}(6-18)}[\mathrm{dB}]$ & 81.2 & $85^{* * *}$ \\
\hline$L_{\mathrm{EX}, 8 \mathrm{~h}(18-6)}[\mathrm{dB}]$ & 56.0 & $85^{* * *}$ \\
\hline$L_{\mathrm{EX}, 8 \mathrm{~h}(6-22)}[\mathrm{dB}]$ & 81.2 & $85^{* * *}$ \\
\hline$L_{\mathrm{EX}, 8 \mathrm{~h}(22-6)}[\mathrm{dB}]$ & 51.2 & 6 \\
\hline
\end{tabular}

* The variability of allowable noise levels, which takes into account the kind of place and object, the activity being the noise source as well as periods to which noise levels are referred, are determined in the Regulation of the Minister of Environment (2013).

** The variability of allowable noise levels, which takes into account the accommodation destination, noise source kind and periods to which noise levels are referred, are determined in the Polish Standard (PN-87/B-02151/02, 1987).

*** The values of these noise indicators were compared with the allowable values in the work environment specified in the Regulations of the Minister of Labour and Social Policy (2014) because the authors take into account protection of human hearing and the fact that the work time and other periods of human activity are not separated in this paper. 


\section{Discussions and conclusions}

Regulations concerning the environment protection, especially the long-term average sound level $L_{\mathrm{DEN}}$ and the long-term night sound level $L_{\mathrm{N}}$ are protecting the environment against human activities, however, only indirectly take into consideration the wellness of humans using the environment. If this assumption is widened into the human noise hazard a significant excess of contractual levels occurs. The measured level of the long-term average sound $L_{\mathrm{DEN}(24 \mathrm{~h})}$ level equals $76.5 \mathrm{~dB}$ and is in excess from 6.5 to $31.5 \mathrm{~dB}$, which can be an essential hazard. Also in the case of the day time sound level $L_{\mathrm{D}(6-22)}$, excesses of allowable values are from $11.5 \mathrm{~dB}$ to $29.5 \mathrm{~dB}$, while for the night sound level $L_{\mathrm{N}(22-6)}$ these excesses can reach to $6.2 \mathrm{~dB}$. The diversity of excesses depends on the classification of the place in which noises occur in the local development plan.

Analyses of the results presented in Table 2 indicate that noise indicators in the work environment were not exceeded. However, the allowable values of five indicators related to the environment, i.e., $L_{\mathrm{D}(6-22)}$, $L_{\mathrm{N}(22-6)}, L_{\text {Aeq, D }}, L_{\text {Aeq, N }}, L_{\mathrm{DEN}(24 \mathrm{~h})}$ were exceeded. It is essential that it is difficult to state explicitly, whether the given person was really subjected to the influence of the exceeding standard noises, since values determined in the legal regulations require controlling and recording of several not acoustic parameters (among others related to the place or to the noise source), which were not recorded.

The study undertakes the problem of assessment of noise hazards during 24-hour activity of a human. The amount of existing indicators - presented in the hereby paper - can indicate the complexity of the problem. These indicators were developed to determine the noise hazard to which a human is subjected. Presently, there are separate indicators concerning assessing noise exposures in work places, residences, or the given localisation. However, they do not take into consideration the holistic approach allowing assessment of 24hour activity of a human, who is subjected to noises in several places, partially. It results from the performed measurements that a person is exposed to noises not only in the work place but also in urban and transport environment, in places of active resting and in residences.

The results of the noise exposure of one person (employee of a coal yard) were presented in this study. The tested person was equipped with the PINH, which recorded the A-weighted sound pressure level for 24 hours. On the basis of the performed investigations 18 indicators, characterising the influence degree on the human hearing organ, were determined with using the existing standards and regulations. These indicators are related to the external environment as well as to the work environment. The majority of these indica- tors, i.e., 15, have the determined allowable values in legal regulations and standards (Table 2). Their values are diversified depending on of several factors, such as the place classification in the local development plan, time of the day, and the source generating noises.

The hereby study is an attempt to show the need of developing a new indicator describing the 24-hour exposure to noise, because currently there is no such indicator. Such a parameter, apart from exposures to noises at workplace has to take into account exposures when other activities are undertaken. In addition, determining its allowable value will allow to determine the noise hazard for a human during a 24-hour period. However, the realisation of such an objective is related to the need of a 24-hour long monitoring of noise hazard, which can be realised by means of the PINH described in (KorBIEL et al., 2014). In cases where continuous registration cannot be carried out the value of the new indicator can be estimated based on the probability distribution (BATKo, PrZYsucha, 2010) or Bayesian inference (BATKo, StęPIEŃ, 2011). There is no doubt that estimate of this parameter will be subject to uncertainty and an estimated result is complete only when it is accompanied by a statement of the associated uncertainty. The uncertainty of human noise exposure can be evaluated based on non-classical approach (BATKo, PAWLik, 2012b; StęPień, 2016).

Development of such an indicator can be very useful in the hearing organ medical diagnosis. Especially, it opens possibility for prediction of further hearing deterioration, in the cases when the acoustic environment (professional or private) remains unchanged. It also allows to make people - endangered by the hearing loss - aware of their habits and to direct them towards the hearing protection in the future.

\section{Acknowledgments}

This paper is based on the results of a research task carried out within the scope of the third stage of the National Programme "Improvement of safety and working conditions" partly supported in 2014-2016 within the scope of research and development - by the Ministry of Science and Higher Education/National Centre for Research and Development. The Central Institute for Labour Protection - National Research Institute (CIOP-PIB) was the Programmer's main coordinator. Investigations were financed from the statute resources of the Department of Mechanics and Vibroacoustics of AGH University of Science and Technology (project No. 11.11.130.955).

\section{References}

1. Amendment to the Act - Environment Protection Law and some other Acts (Act of May 18, 2005) (Journal of Laws 2005, no. 113, item 954). 
2. Announcement of the Marshal of the Polish Sejm of April 19, 2016, concerning the uniform text of the Act - Environment Protection Law (Journal of Laws 2016, item 672).

3. Announcement of the Minister of Environment of October 15, 2013, concerning the uniform text of the Regulation of the Minister of Environment on allowable noise levels in the environment (Journal of Laws 2014, item 112).

4. Announcement of the Minister of Health of November 4, 2016, concerning the uniform text of the Regulation of the Ministry of Health and Social Welfare on medical examinations of employees, prophylactic health care and medical certificates issued for the purposes provided for in the Labour Code (Journal of Laws 2016, item 2067).

5. Batko W., Korbiel T., Barański R., Pawlik P., Blaut J., Stępień B. (2016), A method of assessment noise exposure level and indicator of noise exposure level [in Polish: Sposób oceny poziomu ekspozycji na hałas $i$ wskaźnik poziomu ekspozycji na hałas], PL Patent P-417 257, 19.05.2016.

6. Batko W., PaWlik P. (2012), Uncertainty evaluation in modelling of acoustic phenomena with uncertain parameters using interval arithmetic, Acta Physica Polonica A, 121, 1-A, A-152-A-155, doi: 10.12693/APhysPolA.121.A-152.

7. Batko W., Przysucha B. (2010), Determination of the probability distribution of the mean sound level, Archive of Acoustics, 35, 4, 543-550, doi: 10.2478/v10168-010-0041-1.

8. Batko W., StęPIEŃ B. (2011), Application of the Bayesian inference for estimation of the longterm noise indicators and their uncertainty, Acta Physica Polonica A, 119, 6-A, 916-920, doi: 12693/APhysPolA.119.916.

9. Dzhambov A.M., Dimitrova D.D. (2016), Association between noise pollution and prevalent ischemic heart disease, Folia Med (Plovdiv), 58, 4, 273-281, doi: 10.1515/folmed-2016-0041.

10. European Parliament (2002), Directive 2002/49/EC of the European Parliament and of the Council of 25 June 2002 relating to the assessment and management of environmental noise.

11. Hafke-Dys H.Z., Preis A., Kaczmarek T., BiniaKOWski A., KLEKA P. (2016), Noise annoyance caused by amplitude modulated sounds resembling the main characteristics of temporal wind turbine noise, Archives of Acoustics, 41, 2, 221-232, doi: 10.1515/aoa-20160022 .

12. Hotz M.A., Probst R., Harris F.P., Hauser R. (1993), Monitoring the effects of noise exposure using transiently evoked otoacoustic emission, Acta Otolaryngology, 113, 4, 478-482, doi: 10.3109/00016489309135849.

13. Jaroszewski A. (2000), The extent of hearing damage from exposures to music, Noise \& Vibration Worldwide, 31, 2, 14-25, doi: 10.1260/0957456001497319.
14. KoradeckA D. [Ed.] (2010), Handbook of occupational safety and health, CRC Press, doi: 10.1201/EBK1439806845.

15. Korbiel T., Batko W., Barański R., Pawlik P., BlaUt J. (2014), The risk management by prediction of exposure to noise in marine conditions [in Polish: Zarzadzanie ryzykiem poprzez predykcje ekspozycji na hałas $w$ warunkach okrętowych], Logistyka, 6, CD 2, 835-839.

16. Kosala K., Stępień B. (2016), Analysis of noise pollution in an andesite quarry with the use of simulation studies and evaluation indices, International Journal of Occupational Safety and Ergonomics, 22, 1, 92-101, doi: 10.1080/10803548.2015.1106702.

17. Makarewicz R., Ga€uszka M., Kokowski P. (2014), Evaluation of aircraft noise measurements, Noise Control Engineering Journal, 62, 2, 83-89, doi: $10.3397 / 1 / 376208$.

18. Pawlaczyk-Łuszczyńska M., Dudarewicz A., ZaMOJSKA M. (2010), Minimizing the risk of hearing impairment in the workplace [in Polish: Minimalizowanie ryzyka uszkodzenia słuchu $w$ miejcu pracy], Publishing Office of Nofer Institute of Occupational Medicine, Łódź, Poland.

19. PN-87/B-02151/02 (1987), Building acoustics. Protection against noises in accommodations. Allowable values of sound levels in accommodations.

20. PN-EN ISO 9612:2011 (2011), Acoustics. Determination of occupational noise exposure. Engineering method.

21. Regulation of the Minister of Environment concerning detailed requirements, of the programme of the environment protection against noises (2002), (Journal of Laws 2002, no. 179, item 1498).

22. Regulation of the Minister of Labour and Social Policy dated of June 6, 2014, concerning the highest allowable concentrations and intensities of harmful agents in the work environment (Journal of Laws 2014, item 817).

23. Report of an International Expert Symposium on the usefulness of Otoacoustic Emissions (OAE) Testing in Occupational Health Surveillance (2011), Health \& Safety Executive, Manchester, UK.

24. StęPIEŃ B. (2016), Bootstrap confidence intervals for noise indicators, Acta Acustica united with Acustica, 102, 2, 389-397, doi: 10.3813/AAA.918955.

25. Swinburn T.K., Hammer M.S., Neitzel R.L. (2015), Valuing quiet: an economic assessment of U.S. environmental noise as a cardiovascular health hazard, American Journal of Preventive Medicine, 49, 3, 345353, doi: 10.1016/j.amepre.2015.02.016.

26. Wszolek T., KŁaczyński M., Mleczko D., OzGA A. (2014), On certain problems concerning environmental impact assessment of wind turbines in scope of acoustic effects, Acta Physica Polonica A, 125, 4-A, A-38-A-44, doi: 10.12693/APhysPolA.125.A-38. 